University of Wollongong

Research Online

Faculty of Engineering and Information

Faculty of Engineering and Information

Sciences - Papers: Part B

Sciences

2017

\title{
Behaviour of circularized and FRP wrapped hollow concrete specimens under axial compressive load
}

Mohammed Jameel

University of Wollongong, mtjj932@uowmail.edu.au

M Neaz Sheikh

University of Wollongong, msheikh@uow.edu.au

Muhammad N. S Hadi

University of Wollongong, mhadi@uow.edu.au

Follow this and additional works at: https://ro.uow.edu.au/eispapers1

Part of the Engineering Commons, and the Science and Technology Studies Commons

Research Online is the open access institutional repository for the University of Wollongong. For further information contact the UOW Library: research-pubs@uow.edu.au 


\title{
Behaviour of circularized and FRP wrapped hollow concrete specimens under axial compressive load
}

\author{
Abstract \\ Circularizing a square column by bonding concrete segments onto the sides of the column and then \\ wrapping with fibre reinforced polymer (FRP) is considered an effective technique in strengthening square \\ solid columns. This paper investigates the suitability of the circularization technique for strengthening \\ square hollow concrete specimens. Eight specimens in two groups (four solid specimens and four hollow \\ specimens) were cast and tested under axial compression. The first specimen from each group was the \\ reference specimen. The corners of the second specimen were rounded to $20 \mathrm{~mm}$ radius and wrapped \\ with two layers of carbon fibre reinforced polymer (CFRP). The third specimen was circularized with full \\ length concrete segments and wrapped with two layers of CFRP. The fourth specimen was circularized \\ with concrete segments shorter than the length of the specimen and wrapped with two layers of CFRP. \\ The test results demonstrate that circularization of hollow specimens similar to the circularization of \\ solid specimens reduces the stress concentration at the corners and enhances the ultimate load carrying \\ capacity and ductility. The circularization with short concrete segments is more effective for hollow \\ specimens than the circularization with full length concrete segments when the ductility is of main \\ concern.

\section{Disciplines} \\ Engineering | Science and Technology Studies

\section{Publication Details} \\ Jameel, M. T., Sheikh, M. Neaz. \& Hadi, M. N. S. (2017). Behaviour of circularized and FRP wrapped hollow \\ concrete specimens under axial compressive load. Composite Structures, 171 538-548.
}




\title{
Behaviour of Circularized and FRP Wrapped Hollow Concrete Specimens under Axial Compressive Load
}

\author{
Mohammed Jameel $^{1}$, M. Neaz Sheikh ${ }^{2}$ and Muhammad N.S. Hadi ${ }^{3}$
}

\begin{abstract}
Circularizing a square column by bonding concrete segments onto the sides of the column and then wrapping with fibre reinforced polymer (FRP) is considered an effective technique in strengthening square solid columns. This paper investigates the suitability of the circularization technique for strengthening square hollow concrete specimens. Eight specimens in two groups (four solid specimens and four hollow specimens) were cast and tested under axial compression. The first specimen from each group was the reference specimen. The corners of the second specimen were rounded to $20 \mathrm{~mm}$ radius and wrapped with two layers of carbon fibre reinforced polymer (CFRP). The third specimen was circularized with full length concrete segments and wrapped with two layers of CFRP. The fourth specimen was circularized with concrete segments shorter than the length of the specimen and wrapped with two layers of CFRP. The test results demonstrate that circularization of hollow specimens similar to the circularization of solid specimens reduces the stress concentration at the corners and enhances the ultimate load carrying capacity and ductility. The circularization with short concrete segments is more effective for hollow specimens than the circularization with full length concrete segments when the ductility is of main concern.
\end{abstract}

Keywords: column; CFRP; circularization; concrete segments; axial compression; hollow; ductility.

1 PhD Candidate, School of Civil, Mining and Environmental Engineering, University of Wollongong, Wollongong NSW 2522 Australia. E-mail: mtji932@uow.edu.au

2 Senior lecturer, School of Civil, Mining and Environmental Engineering, University of Wollongong, Wollongong NSW 2522 Australia. E-mail: msheikh@uow.edu.au

3 Associate Professor, School of Civil, Mining and Environmental Engineering, University of Wollongong, Wollongong NSW 2522 Australia (corresponding author). E-mail: $\underline{\text { mhadi@uow.edu.au }}$ 


\section{Introduction}

Fibre reinforced polymer (FRP) has become popular in retrofitting and strengthening structural members. FRP is a non-corrosive and non-magnetic material and has high strengthto-weight ratio. FRP wrapping around concrete columns improves the strength and ductility of the columns [1-5].

Hollow column is usually preferred in the construction of piers of tall bridges to maximise the strength-mass and stiffness-mass ratios of the structure, to reduce the amount of construction material and to reduce the weight on foundation. Hollow columns are economical compared to solid columns. However, hollow columns may experience brittle failure due to the existence of an inner hole. Unlike solid columns, wrapping hollow columns with FRP subjects the concrete to a bi-axial state of stress instead of a tri-axial state of stress [6]. Hence, FRP confinement is more effective in solid columns than hollow columns [7]. Moreover, the FRP confinement efficiency depends on the ratio of the diameter of the hole $\left(R_{i}\right)$ to the diameter of the column $\left(R_{o}\right)$. For the increase in the $R_{i} / R_{o}$ ratio, the strength gain from FRP wrapping decreases while the ductility increases $[8,9]$.

The efficiency of FRP confinement is higher for circular columns than for non-circular columns. The stress concentration at corners and the reduced effective area of confinement compromise the confinement efficiency of non-circular columns [7, 10-19]. Similarly, wrapping of hollow circular columns with FRP produces better enhancement in strength and ductility than the wrapping of non-circular hollow columns [7, 20-23].

Changing the square column into a circular column before FRP wrapping may minimize the stress concentration and improve the confinement efficiency. Shape modification was first experimentally investigated by bonding precast concrete bolsters to the square solid column before FRP wrapping by Priestley and Seible [23]. It was found that the confinement efficiency increased after the shape modification. A fast-cured cement was used to fill the gap between the FRP straps and non-circular solid column to modify the shape of the crosssection into a circular in Saadatmanesh et al. [24]. Yan et al. [25] and Yan and Pantelides [26] used expansive cement and FRP to modify the shape of columns from square and rectangular into circular and elliptical, respectively. The results showed that the confinement changed 
from passive to active, the axial load capacity increased and the stress-strain curve changed from softening to hardening branch.

Hadi et al. [27] proposed a new method for strengthening square solid RC columns by modifying the square column into a circular with four precast concrete segments and FRP wrapping. The compressive strength of concrete for the columns and the concrete segments was the same. The test results showed that the confinement efficiency in terms of strength and ductility of the columns increased after the shape modification. The advantages of the proposed method are that the cost of rounding the corners of the column can be reduced and precast concrete segments can be constructed efficiently in factories. Pham et al. [28] used concrete segments constructed with concrete of compressive strength 40 to $100 \mathrm{MPa}$ to change the shape of square columns into circular columns and the modified circular columns were wrapped with CFRP. It was reported that the load carrying capacity of the modified circular solid columns increased with the increase of the compressive strength of the concrete segments.

The above literature review shows that previous studies on shape modification were carried out on solid square and rectangular columns. This paper investigates the effect of shape modification on square hollow specimens.

\section{Experimental Program}

\subsection{Design of Specimens}

A total of eight specimens made from normal strength concrete were cast and tested at the University of Wollongong, Australia. The specimens were divided into two groups: solid and hollow specimens. All the specimens were $300 \mathrm{~mm}$ in height and $106 \mathrm{~mm}$ x $106 \mathrm{~mm}$ in crosssection. The hollow specimens had a central square hole of $40 \mathrm{~mm}$ sides. Each group consisted of four specimens. The first specimen in each group was the reference specimen. The second specimen constructed with $20 \mathrm{~mm}$ round corners and was wrapped with two layers of CFRP, which simulates the conventional strengthening method. The third specimen was circularized with full length plain concrete segments and wrapped with two layers of CFRP. The fourth specimen was circularized with concrete segments which were $20 \mathrm{~mm}$ 
shorter than the length of the specimen and wrapped with two layers of CFRP. All specimens were tested under axial compression loading.

The test matrix is shown in Table 1. In column 1 of Table 1, the first letter of the specimens is either the $\mathrm{S}$ or $\mathrm{H}$, where $\mathrm{S}$ refers to solid specimen and $\mathrm{H}$ refers to hollow specimen. The remaining letters refer to the strengthening method. $\mathrm{N}$ refers to no modification, RF refers to round corners and then CFRP wrapped, LCF refers to circularized with full length concrete segments and then CFRP wrapped, and SCF refers to circularized with concrete segments shorter than the length of the specimen and then CFRP wrapped. For example, Specimen SLCF refers to the solid specimen circularized with full length concrete segments and wrapped with CFRP. Specimen HSCF refers to the hollow specimen circularized with short concrete segments and wrapped with CFRP. The cross-sections and geometries of the specimens are shown in Fig.1.

\subsection{Formwork Design}

The formwork of the specimens was made from plywood. For the hollow specimens, the hollow part was made from $40 \mathrm{~mm}$ square foam with a height of $300 \mathrm{~mm}$. An $8 \mathrm{~mm}$ steel rod was inserted through the foam and fixed into the base plate of the formwork to align the foam vertically. The round corners of Specimens SRF and HRF were created by gluing arched shape foam with $20 \mathrm{~mm}$ radius and $300 \mathrm{~mm}$ height into the inner corners of the square formwork. In order to make the concrete segments, square (106 mm x $106 \mathrm{~mm}$ ) plywood frames were fitted into steel cylinders (150 $\mathrm{mm}$ inside diameter and $300 \mathrm{~mm}$ height). Heights of the concrete segments were $300 \mathrm{~mm}$ and $280 \mathrm{~mm}$ to provide full length concrete segments and short concrete segments, respectively. Each cylinder generated four concrete segments. Details of the formworks are shown in Fig. 2.

\subsection{Material Properties}

A ready mix concrete with a nominal compressive strength of $40 \mathrm{MPa}$ at 28 days was used in this study. The concrete was provided by a local supplier with $150 \mathrm{~mm}$ slump and maximum aggregate size of $10 \mathrm{~mm}$. The strength of the concrete was determined by testing small concrete cylinders with $100 \mathrm{~mm}$ diameter and $200 \mathrm{~mm}$ height according to AS1012.9 [29]. 
The average compressive strength of concrete at 28 days was $40 \mathrm{MPa}$ and the average compressive strength of concrete during the testing period was $45 \mathrm{MPa}$.

Unidirectional CFRP of $100 \mathrm{~mm}$ width and $200 \mathrm{~g} / \mathrm{m}^{2}$ density was used as confinement material. The mechanical properties of CFRP were determined by flat coupon tests according to ASTMD7565 [30]. The average width of the tested coupons for the two layers of CFRP was $25.4 \mathrm{~mm}$. The average maximum tensile force per unit width was $1102 \mathrm{~N} / \mathrm{mm}$. The strain at the maximum tensile force and the elastic modulus of the CFRP were $0.0163 \mathrm{~mm} / \mathrm{mm}$ and $67.5 \mathrm{kN} / \mathrm{mm}$, respectively.

\subsection{Specimen Preparation}

\subsubsection{Specimen Circularization}

Before the circularization process, the surfaces of the specimens were cleaned to remove any dust and to ensure that the surfaces are smooth. The shape of Specimens SLCF and HLCF was changed into circular by bonding four full length concrete segments of $300 \mathrm{~mm}$ length. For Specimens SSCF and HSCF, concrete segments with $280 \mathrm{~mm}$ length which are shorter than the length of the specimen were bonded to the sides of the specimens $(10 \mathrm{~mm}$ at both top and bottom of the specimens were left without circularization). A mixture of epoxy resin, slow hardener and silica microsphere with a ratio of 5:1:10 was used as glue between the specimens and the bonded concrete segments. The glue was evenly spread onto the surfaces of both the specimen and the concrete segments. The concrete segments were then attached to the surface of the specimen. The circularized specimens were left to dry for three days. Bonding of concrete segments to the concrete specimens is shown in Fig. 3.

\subsubsection{CFRP Wrapping}

All specimens, except Specimens SN and HN were wrapped with two layers of CFRP. The specimens were wrapped using wet-layup method. A mixture of epoxy resin and hardener at a ratio of 5:1 was used as an adhesive. At first, the surface of the specimen was cleaned and 
then the epoxy resin was spread onto the surface and the first CFRP layer was attached. After that, epoxy resin was spread onto the surface of the first CFRP layer and then the second layer was attached. An overlap of $100 \mathrm{~mm}$ was maintained at the second layer. The epoxy resin was then spread onto the final layer. An additional two layers of CFRP was wrapped with $50 \mathrm{~mm}$ width at top and bottom ends of all the specimens to prevent premature failure during testing.

\subsection{Instrumentation and Test Procedures}

The universal Denison compressive testing machine with a maximum load capacity of 5000 $\mathrm{kN}$ in the High Bay laboratory at the University of Wollongong, Australia was used to determine the strength and to monitor the axial deformation of the specimens. The specimens circularized with full length concrete segments were capped at both ends using high-strength plaster. All other specimens were capped at one end only. The specimens were capped to ensure an even distribution of the applied load on the loaded face. To determine the axial deformation of the specimens, a Linear Variable Differential Transducer (LVDT) was used. For the circularized specimens, the LVDT was mounted onto a frame of two circular rings. For square specimens, a square test setup was designed. The travel linear variable differential transformer (LVDT) was mounted onto two box frames that were fixed at the top and bottom of the specimen by steel bolts. The box frames were balanced by three arms with specific length, to ensure the even level of the top box frame as the bottom box frame were levelled by three pieces of same height. Before starting the test, two of the arms were removed while the third one was pinned into the upper box frame with a gap to keep free movement. The details of the test setup are shown in Fig. 4. In addition, two LVDTs were attached to the lower moving plate of the Universal testing machine after setting the specimens in the testing machine. The LVDTs were connected to a data logger which was connected to a computer to record the data. All specimens were tested under a displacement controlled axial load at the rate of $0.5 \mathrm{~mm} / \mathrm{min}$. The data were recorded at every two seconds.

\section{Experimental Results}

\subsection{Failure Mode}


All specimens were tested to failure. Failure modes of the specimens are shown in Fig. 5. The failure of Specimens SN and HN was brittle and sudden. The failure was due to spalling and crushing of the concrete.

The failure of Specimens SRF and HRF was initiated by a snapping sound. Afterwards, the stretching of the CFRP was observed at mid-height in one of the corners, causing the axial load to drop. The stretching of the CFRP continued at the corner with the crushing and dilation of concrete accompanied by the reduction in the axial load.

For Specimens SLCF and HLCF, the failure was initiated with an explosive sound. The explosive failure indicates the release of a large amount of energy due to the high confinement pressure as a result of the uniform confining stress provided by the CFRP.

For Specimen SSCF a loud snapping sound from the mid-height of the specimen was heard when the axial load approached the ultimate axial load. The first CFRP ring ruptured at midheight. Afterwards, the next upper and lower CFRP rings ruptured. The CFRP rupture was accompanied by the reduction in the axial load until the CFRP straps completely stretched and concrete exposed at mid-height. The rupture of the CFRP revealed that the concrete segments were cracked longitudinally into big fragments and bent outwards at mid-height. Unlike the solid specimens, the rupture of the CFRP at mid-height of Specimen HSCF revealed that the concrete segments were cracked into small fragments.

Fig. 6 shows the effect of confinement on the hole of the hollow specimens. Crushing of concrete was observed at the hole (Fig. 6 (e)). In addition, the concrete at the walls of the inner hole was cracked and spalled off. Also, the shape of the hole changed from square to circular. The change of shape was clearer for Specimen HRF (Fig. 6 (b)). The inner hole of Specimen HN was not changed, as the specimen was not confined (Fig. 6 (a)).

\subsection{Load- Deformation Behaviour}

\subsubsection{Solid Specimens}


Fig. 7 shows the axial load-axial deformation behaviour of the solid specimens. The test results of the solid specimens are summarised in Table 2. The axial load-axial deformation curve of all the specimens is linear up to yield load at the first part which represents the unconfined concrete. After the yield, the axial load of Specimen SN decreased quickly to failure. The axial load of the CFRP confined specimens (Specimens SRF, SLCF and SSCF) increased after the yield with another slope of the axial load-axial deformation curve up to failure. Afterwards, the axial load dropped suddenly due to the rupture of the CFRP, debonding of the CFRP and concrete crushing. The highest ultimate axial load was achieved by Specimen SLCF followed by Specimen SSCF and Specimen SRF. The increase in the ultimate axial load was 222\%, $73 \%$ and $57 \%$ for Specimens SLCF, SSCF and SRF, respectively, relative to the ultimate axial load of Specimen SN. Specimen SSCF showed only $10 \%$ higher ultimate axial load compared to Specimen SRF. The higher ultimate axial load in Specimen SSCF compared to Specimen SRF was due to the shape modification only, as the loaded cross-sectional areas of specimens SSCF and SRF were nearly the same.

The ductility of the specimens was determined as the ratio of the axial deformation corresponding to $85 \%$ of ultimate axial load in the post ultimate region [31] or the axial deformation corresponding to the rupture of CFRP $\left(\delta_{\mathrm{u}}\right)$ and the deformation at the yield $\left(\delta_{\mathrm{y}}\right)$. The yield deformation was defined as the axial deformation corresponding to the intersection point of an extension line through the origin and $75 \%$ of the first peak axial load with the horizontal line from the ultimate axial load [32]. For the CFRP confined specimens with an ascending behaviour in the axial load-axial deformation curve after yield which represents the second portion, the yield deformation was defined as the axial deformation corresponding to the intersection point of an extension line through the origin and $75 \%$ of the first peak axial load with the best fit line of the second linear potion.

The increase in the ductility was 331\%, 307\%, and 230\% for Specimens SRF, SLCF and SSCF, respectively, relative to the ductility of Specimen SN. Specimen SSCF showed better enhancement in ductility than the enhancement in the ultimate axial load. The high ductility and comparatively low axial load of Specimen SSCF were because the axial load was applied to the square specimen only. Hence, the dilation of the concrete of the square specimen and the CFRP confinement subjected the concrete segments under bi-axial state of stress. Therefore, the concrete segments expanded in the axial direction due to Poisson's effect. The yielding of the concrete segments reduced the confinement pressure. Afterwards, the concrete 
segments cracked into big parts with sharp edges. The sharp edges caused a premature failure to the CFRP at mid-height of the specimen. Specimens SRF and SLCF showed similar enhancement in ductility.

Specimens SRF and SLCF showed nearly bi-linear axial load-axial deformation curve with ascending branch of the second part which represents the confined concrete. The ascending second part confirms the increased confinement provided by the CFRP. On the other hand, Specimen SSCF showed a slight decrease in axial load after the yielding. The slight decrease in the axial load showed that the gain from confinement was less than the concrete degradation due to the yielding of concrete segments when the square specimen dilated and CFRP activated. Li et al. [33] reported that when the gain of confinement is higher than concrete degradation, the axial load-axial deformation curve shows an ascending behaviour and vice versa. Afterwards, the axial load-axial deformation curve of Specimen SSCF rose again up to failure. The slope of the second part of the axial load-axial deformation curve is steeper for Specimen SLCF than Specimen SSCF. Specimen SLCF was considered to be more effectively confined than Specimen SSCF. Specimen SLCF more effectively confined than Specimen SSCF because the concrete of the concrete segments of Specimen SLCF was also confined as the concrete segments were subjected to the applied axial load. Hence, the concrete segments of Specimen SLCF were subjected to tri-axial state of stress. The slope of the second part of the axial load-axial deformation curve is steeper for Specimen SSCF than Specimen SRF due to the increased confinement of Specimen SSCF resulted from the circularization.

\subsubsection{Hollow Specimens}

Fig. 8 shows the axial load-axial deformation behaviour of the hollow specimens. The test results of the hollow specimens are summarised in Table 2. Specimens HRF, HLCF and HSCF sustained 19\%, 177\% and 68\%, respectively, higher ultimate axial load compared to Specimen HN. Specimens HRF, HLCF and HSCF sustained 257\%, 272\% and 335\%, respectively, higher ductility compared to Specimen HN. The slight increase in the ultimate axial load of Specimen HRF compared to Specimen HN was due to the stress concentration at the corners. Also, the existence of the hole reduced the confinement efficiency of Specimen HRF. Specimen HLCF showed the highest ultimate axial load followed by Specimen HSCF and Specimen HRF. Specimen HSCF sustained the highest ductility 
followed by Specimen HLCF and Specimen HRF. Similar to the solid specimen (Specimen SSCF), the high ductility of Specimen HSCF was due to the yielding of the concrete segments as the axial load was applied to the square hollow concrete specimen only. However, the hole in the hollow specimen and the yielding of the concrete segments reduced the outward pressure and delayed the rupture of the CFRP. Therefore, Specimen HSCF achieved significant increase in the ultimate axial load and the concrete segments cracked into small fragments at failure. Specimen HRF experienced second peak in the axial loadaxial deformation curve with the maximum axial load slightly lower than the axial load in the first peak. Afterwards, the axial load capacity decreased sharply. Kusumawardaningsih and Hadi [7] also reported two peak loads for the hollow square columns confined with CFRP. Specimen HSCF experienced a decrease in the axial load after the first peak axial load as the hole reduced the confinement pressure. Afterwards, the axial load increased up to failure load in which the failure load was much higher than the first peak axial load. The increased axial load was due to the increased confinement from the circularization. Also the increased wall thickness reduced the ratio of the diameter of the hole $\left(R_{i}\right)$ to the diameter of the column $\left(R_{o}\right)$. Lignola et al. [8] reported that a smaller ratio of $R_{i} / R_{o}$ increases the confinement of the FRP confined hollow columns.

\subsection{Theoretical Ultimate Axial Load of Solid and Hollow Specimens}

A simplified theoretical model for the ultimate axial load of solid and hollow specimens has been developed herein. The FRP confinement model in Lam and Teng [16] was adopted to determine the ultimate axial load of FRP confined square and circularized solid specimens. The compressive strength of confined concrete was expressed as:

$$
\begin{array}{r}
f_{c c}^{\prime}=f_{c o}^{\prime}\left(1+3.3 k_{a} \frac{f_{l}}{f_{c o}^{\prime}}\right) \\
f_{l}=\left(\frac{2 k_{e} f_{f r p} t}{D}\right) \\
k_{a}=\left(\frac{b}{h}\right)^{2} \frac{1-\left(\left(b-2 R_{c}\right)^{2}+\frac{\left(h-2 R_{c}\right)^{2}}{3 A_{c}}\right)-\rho_{s c}}{1-\rho_{s c}}
\end{array}
$$


The equivalent outer diameter of square column was determined as follows:

$$
D=\sqrt{2 b^{2}}
$$

where $f_{c o}^{\prime}$ is the unconfined compressive strength of concrete, $t$ is the thickness of FRP, $f_{f r p}$ is the rupture stress of FRP, $D$ is the diameter of columns, $k_{e}$ is the strain efficiency factor which was taken as 0.586 as proposed in Lam and Teng [16], $k_{a}$ is the shape factor, $A_{c}$ is the cross-section area, $p_{s c}$ is the ratio of longitudinal steel reinforcement to the cross-section area and $b$ is the side length of square column.

Lignola et al. [8] showed that the efficiency FRP confinement of hollow specimens decreased with the increase of $\frac{D_{h}}{D}$, where $D_{h}$ is the diameter of hole. In this study, a factor $\beta$ was introduced to determine the axial compressive strength of FRP confined square and circularized hollow specimens as:

$$
\begin{array}{r}
f_{c c}^{\prime}=f_{c o}^{\prime}\left(1+3.3 k_{a} \frac{f_{l}^{\prime}}{f_{c o}^{\prime}}\right) \beta \\
\beta=1-\frac{D_{h}^{2}}{D^{2}}
\end{array}
$$

The equivalent diameter of square hole in this study was determined as:

$$
D_{h}=\sqrt{2 b_{h}^{2}}
$$

where $b_{h}$ is the side length of square hole. 
For solid specimen circularized with short concrete segments and wrapped with CFRP (Specimen SSCF), the loaded square area of specimen was considered under triaxial state of stresses, while the unloaded short segments were considered under biaxial state of stresses. Hence, the axial compressive strength of Specimen SSCF was determined as:

$$
f_{c c}^{\prime}=f_{c o}^{\prime}\left(1+3.3 k_{a} \frac{f_{l}}{f_{c o}^{\prime}}\right)\left(\frac{A_{s e g} \beta+A_{s q}}{A_{s e g}+A_{s q}}\right)
$$

Where $A_{s q}$ is the square loaded area of the specimen and $A_{s e g}$ is the unloaded area of the short segments.

The compressive strength of hollow specimens circularized with short segments was assumed to be similar to that of full length circularized hollow specimens, because in both cases the concrete of segments was under biaxial state of stresses.

The ultimate axial load of the specimens was determined by multiplying the predicted ultimate compressive strength $\left(f_{c c}^{\prime}\right)$ with the loaded cross-section area of the specimen as:

$$
P_{u=} f_{c c}^{\prime} A_{c}
$$

Table 3 shows the experimental and theoretical ultimate axial load of the tested specimens. The ratio between the theoretical and experimental ultimate axial load for solid and hollow specimens varies from 0.79 to 1.03 . The ratio between the theoretical and experimental ultimate axial load has been observed to be the lowest for specimens circularized with short concrete segments for both solid and hollow specimens. It can be observed that the developed simplified theoretical model reasonably predicts the ultimate axial load of FRP confined square and circularized solid and hollow specimens of this study (Table 3).

\section{Discussion}

4.1. Comparison between Solid and Hollow tested Specimens 
Fig. 9 presents a comparison of the axial load-axial deformation behaviour of the solid and hollow specimens. It can be observed that the axial load carrying capacity was higher for all solid specimens compared to the corresponding hollow specimens.

Specimen SRF experienced a steady increase in the axial load from the yield load to the ultimate axial load and then the axial load dropped suddenly. While for Specimen HRF, the axial load dropped slightly after the yielding because the rate of confinement activation was less than the concrete degradation due to the existence of the unconfined inner hole. Afterwards, the axial load of Specimen HRF increased with a gentle slope of the axial loadaxial deformation curve up to failure.

Specimen SLCF and Specimen HLCF showed increased axial load (ascending axial loadaxial deformation curve) after the yielding up to failure. The ascending behaviour of the axial load-axial deformation curve of Specimen SLCF was because the rate of confinement activation was higher than the rate of concrete degradation. However, the slope of the axial load-axial deformation curve after the yielding was steeper for Specimen SLCF than that of Specimen HLCF due to the presence of the hole in Specimen HLCF. Specimen SSCF showed a decrease in the axial load after the yielding from $672 \mathrm{kN}$ to $638 \mathrm{kN}$ due to the yielding of the concrete segments around the circularized specimen, which delayed the confinement activation. Afterwards, the axial load of Specimen SSCF increased slightly up to the ultimate axial load. While the axial load of Specimen HSCF dropped slightly after the yielding from $589 \mathrm{kN}$ to $559 \mathrm{kN}$ then the axial load increased slightly with a slope of the axial load-axial deformation curve less steep than that of Specimen SSCF.

Specimen SLCF achieved higher ductility than Specimen HLCF. Specimen SRF showed higher ductility than Specimen HRF. Specimen HSCF showed higher ductility than Specimen SSCF because the hole reduced the dilation of the concrete toward the outside and delayed the rupture of CFRP.

Table 2 showed that the presence of the hole changed the trend of ductility for hollow specimens compared to solid specimens. With the increase in the applied axial load, the confinement restricts the outward expansion of concrete, while the presence of the hole resulted in an inward expansion. The inward expansion increased with increased confinement efficiency which increased the ductility. Hence, the ductility of Specimen HLCF was higher 
than the ductility of Specimen HRF. Lignola et al. [8] also showed that the existence of hole reduces the strength of hollow specimens while increases the ductility. The short segments of Specimen HSCF expanded towards the axial direction and resulted in higher ductility for specimen HSCF than for Specimen HLCF. On the other hand, the confinement of Specimen SLCF was higher than the confinement of Specimen SRF. Therefore, the failure of Specimen SLCF was sudden and led to lower ductility than Specimen SRF. The cracking of the short segments in Specimen SSCF led to the premature failure of CFRP and reduced the ductility of the specimen.

\subsection{Effect of the Length of Concrete segments}

The specimens (both solid and hollow specimens) circularized with full length concrete segments achieved higher axial load carrying capacity compared to the specimens circularized with short concrete segments, as shown in Fig. 7 and Fig. 8. The ultimate axial load of Specimen SLCF was $86 \%$ higher than the ultimate axial load of Specimen SSCF. The ultimate axial load of Specimen HLCF was $65 \%$ higher than the ultimate axial load of Specimen HSCF. Also, Specimen SLCF achieved 23\% higher ductility compared to Specimen SSCF. While, Specimen HSCF achieved 17\% higher ductility compared to Specimen HLCF. Therefore, the full length concrete segments are more effective in enhancing the behaviour of circularized and CFRP confined solid specimens in terms of strength and ductility than short concrete segments. Full length concrete segments are more effective in enhancing the behaviour of circularized and CFRP confined hollow specimens in terms of strength than short concrete segments. On the other hand, the short concrete segments are more effective in enhancing the ductility of the circularized CFRP confined hollow specimens than the full length concrete segments.

For full length circularized and CFRP confined solid and hollow specimens, full bond was observed between the concrete segments and the square specimen for Specimen SLCF and Specimen HLCF. Hadi et al. [27] also reported the existence of full bond between the concrete segments and the square column after failure. On the other hand, the premature rupture of the CFRP at mid-height of the specimens led the concrete segments to crack before the failure of the square specimen for Specimen SSCF and Specimen HSCF. 


\subsection{Stress-Strain Behaviour}

Axial stress-axial strain diagrams of the tested solid and hollow specimens have been presented in Fig. 10. Unlike Fig. 9 where the contribution of section enlargement had a significant role in increasing the force, Fig. 10 clearly illustrates the effect of the circularization on the behaviour of the CFRP confined solid and hollow specimens. Circularizing solid specimen with full length concrete segments and CFRP wrapping enhanced the performance of the specimen (Specimen SLCF) more from the yield load up to the ultimate axial load than rounding the corners of solid specimen and CFRP wrapping of the specimen (Specimen SRF). On the other hand, the circularization enhanced the performance of the CFRP wrapped hollow specimens (Specimen HLCF and HSCF) only after the yield load compared to rounding the corners of hollow specimen (Specimen HRF). The enhancement in the yield stress gained from circularizing the hollow specimens compared to rounding the corners of hollow Specimens was less. This might be due to the existence of the hole that reduced the confinement effectiveness at the yield stress.

\section{Conclusions}

Circularization proved to be an effective method in strengthening CFRP confined square hollow concrete specimens similar to CFRP confined solid concrete specimens.

The experimental investigations carried out in this paper demonstrated that the specimens circularized with full length concrete segments confined with CFRP achieved higher ultimate axial load than the specimens circularized with short concrete segments confined with CFRP. This enhancement is mainly due to the contribution of the section enlargement and corner mitigation. The hollow specimens circularized with short concrete segments experienced higher ductility than the hollow specimens circularized with full length concrete segments. Therefore, the circularization with short concrete segments is more effective for hollow specimens than the circularization with full length concrete segments when the ductility is of main concern.

When the effect of circularization is compared with rounding the corners of the CFRP confined specimens, after excluding the contribution from section enlargement, the circularization technique contributed less to the yield stress of the hollow specimens than to 
the yield stress of the solid specimens. The contribution to the ultimate axial stress from circularization is significantly more for both hollow and solid concrete specimens than from rounding the corners. A simplified theoretical model was developed to predict the axial load of CFRP confined square and circularized solid and hollow specimens. The developed simplified model reasonably predicts the ultimate axial load of the tested specimens.

\section{Acknowledgment}

The authors acknowledge the contribution of technical officers Mr. Richard Gasser, Mr. Ritchie Mclean for their assistance in testing the specimens. The first author acknowledges the support of the Iraqi Government for his full Ph.D. scholarship.

\section{References}

[1] A. Rahai and H. Akbarpour, "Experimental investigation on rectangular RC columns strengthened with CFRP composites under axial load and biaxial bending," Composite Structures, vol. 108, pp. 538-546, 2014.

[2] M. N. S. Hadi, "Behaviour of FRP wrapped normal strength concrete columns under eccentric loading," Composite Structures, vol. 72, pp. 503-511, 2006.

[3] S. Matthys, H. Toutanji, K. Audenaert, and L. Taerwe, "Axial load behavior of largescale columns confined with fiber-reinforced polymer composites," ACI Structural Journal, vol. 102, pp. 258-267, 2005.

[4] J. Li and M. N. S. Hadi, "Behaviour of externally confined high-strength concrete columns under eccentric loading," Composite Structures, vol. 62, pp. 145-153, 2003.

[5] A. Mirmiran and M. Shahawy, "Behavior of concrete columns confined by fiber composites," Journal of Structural Engineering, vol. 123, pp. 583-590, 1997.

[6] M. N. S. Hadi and T. D. Le, "Behaviour of hollow core square reinforced concrete columns wrapped with CFRP with different fibre orientations," Construction and Building Materials, vol. 50, pp. 62-73, 2014. 
[7] Y. Kusumawardaningsih and M. N. S. Hadi, "Comparative behaviour of hollow columns confined with FRP composites," Composite Structures, vol. 93, pp. 198-205, 2010.

[8] G. P. Lignola, A. Prota, G. Manfredi, and E. Cosenza, "Unified theory for confinement of RC solid and hollow circular columns," Composites Part B, vol. 39, pp. 1151-1160, 2008.

[9] A. Z. Y. H. Fam, "Concrete-filled fibre-reinforced polymer tubes for axial and flexural structural members," 2000.

[10] A. Cascardi, F. Micelli, and M. A. Aiello, "Unified model for hollow columns externally confined by FRP," Engineering Structures, vol. 111, pp. 119-130, 2016.

[11] N. Nisticò, "RC square sections confined by FRP: A numerical procedure for predicting stress-strain relationships," Composites Part B: Engineering, vol. 59, pp. 238-247, 2014.

[12] P. Faustino, C. Chastre, and R. Paula, "Design model for square RC columns under compression confined with CFRP," Composites part B-engineering, vol. 57, pp. 187198, 2014.

[13] P. Colajanni, M. Fossetti, and G. MacAluso, "Effects of confinement level, crosssection shape and corner radius on the cyclic behavior of CFRCM confined concrete columns," Construction and Building Materials, vol. 55, pp. 379-389, 2014.

[14] N. Nisticò and G. Monti, "RC square sections confined by FRP: Analytical prediction of peak strength," Composites Part B: Engineering, vol. 45, pp. 127-137, 2013.

[15] M. A. G. Silva, "Behavior of square and circular columns strengthened with aramidic or carbon fibers," Construction and Building Materials, vol. 25, pp. 3222-3228, 2011. 
[16] L. Lam and J. G. Teng, "Design-oriented stress-strain model for FRP-confined concrete in rectangular columns," Journal of Reinforced Plastics and Composites, vol. 22, pp. 1149-1186, 2003.

[17] K. A. Harries and S. A. Carey, "Shape and "gap" effects on the behavior of variably confined concrete," Cement and Concrete Research, vol. 33, pp. 881-890, 2003.

[18] P. Rochette and P. Labossiere, "Axial testing of rectangular column models confined with composites," Journal of Composites for Construction, vol. 4, pp. 129-136, 2000.

[19] S. Razvi and M. Saatcioglu, "Confinement model for high-strength concrete," Journal of Structural Engineering, vol. 125, pp. 281-289, 1999.

[20] M. Aiello, F. Micelli, and L. Valente, "FRP-Confined Masonry: from Experimental Tests to Design Guidelines," Proceedings of the CICE, 2008.

[21] Y. K. Yeh and Y. L. Mo, "Shear Retrofit of Hollow Bridge Piers with Carbon FiberReinforced Polymer Sheets," Journal of Composites for Construction, vol. 9, pp. 327336, 2005.

[22] C. Bieker, W. Seim, and J. Stürz, "Post-Strengthening of Masonry Columns by use of Fiber-reinforced polymers (FRP)," in Third International Conference of Composites in Infrastructure, San Francisco, 2002.

[23] M. J. N. Priestley and F. Seible, "Design of seismic retrofit measures for concrete and masonry structures," Construction and Building Materials, vol. 9, pp. 365-377, 1995.

[24] H. Saadatmanesh, M. Ehsani, and L. Jin, "Seismic retrofitting of rectangular bridge columns with composite straps," Earthquake Spectra, vol. 13, pp. 281-304, 1997.

[25] Z. Yan, C. P. Pantelides, and L. D. Reaveley, "Fiber-reinforced polymer jacketed and shape-modified compression members: I - Experimental behavior," ACI Structural Journal, vol. 103, pp. 885-893, 2006. 
[26] Z. Yan and C. P. Pantelides, "Concrete column shape modification with FRP shells and expansive cement concrete," Construction and Building Materials, vol. 25, pp. 396-405, 2011.

[27] M. N. S. Hadi, T. M. Pham, and X. Lei, "New method of strengthening reinforced concrete square columns by circularizing and wrapping with fiber-reinforced polymer or steel straps," Journal of Composites for Construction, vol. 17, pp. 229-238, 2012.

[28] T. M. Pham, L. V. Doan, and M. N. S. Hadi, "Strengthening square reinforced concrete columns by circularisation and FRP confinement," Construction and Building Materials, vol. 49, pp. 490-499, 2013.

[29] AS1012.9, "Determination of the compressive strength of concrete specimens," ed: Australian Standard, 1999.

[30] A. D7565, "Standard Test Method for Determining Tensile Properties of Fiber Reinforced Polymer Matrix Composites Used for Strengthening of Civil Structures," ed. ASTM D7565-10, 2010.

[31] S. Pessiki and A. Pieroni, "Axial load behavior of large-scale spirally-reinforced highstrength concrete columns," ACI Structural Journal, vol. 94, pp. 304-314, 1997.

[32] S. J. Foster and M. M. Attard, "Experimental tests on eccentrically loaded high strength concrete columns," ACI Structural Journal, vol. 94, 1997.

[33] G. Li, D. Maricherla, K. Singh, S.-S. Pang, and M. John, "Effect of fiber orientation on the structural behavior of FRP wrapped concrete cylinders," Composite Structures, vol. 74, pp. 475-483, 2006. 


\section{List of Tables}

Table 1. Test matrix

Table 2. Test results of solid and hollow specimens

Table 3. Theoretical and experimental results of the tested solid and hollow specimens 


\section{List of figures}

Fig. 1. Schematic details of the specimens

Fig. 2. Formworks for the specimens and segments

Fig. 3. Preparation of the specimens

Fig. 4. Details of the square circular frames used to hold the LVDT

Fig. 5. Failure mode of the tested specimens

Fig. 6. Effect of confinement on the internal walls of the hollow

Fig. 7. Axial load-axial deformation behaviour of solid specimens

Fig. 8. Axial load-axial deformation behaviour of hollow specimens

Fig. 9. Comparison of axial load-axial deformation behaviour of solid and hollow specimens

Fig. 10. Axial stress-axial strain behaviour of solid and hollow specimens excluding crosssectional area enlargement 
Table1. Test matrix

\begin{tabular}{|c|c|c|c|c|c|}
\hline Specimen & $\begin{array}{c}\text { Cross-section } \\
\operatorname{area}\left(A_{c}\right) \\
\left(\mathrm{mm}^{2}\right) \\
\end{array}$ & $\begin{array}{l}\text { Height } \\
(\mathrm{mm})\end{array}$ & $\begin{array}{c}\text { Hole } \\
\text { dimension } \\
(\mathrm{mm})\end{array}$ & Modification & $\begin{array}{l}\text { External } \\
\text { confinement }\end{array}$ \\
\hline SN & 11236 & 300 & None & None & No \\
\hline SRF & 10893 & 300 & None & 20-mm round corner & 2 layers of CFRP \\
\hline SLCF & 17679 & 300 & None & $\begin{array}{l}\text { Circularization with full } \\
\text { length concrete } \\
\text { segments }\end{array}$ & 2 layers of CFRP \\
\hline $\mathrm{SSCF}$ & 11236 & 300 & None & $\begin{array}{l}\text { Circularization with } \\
\text { Short concrete segments }\end{array}$ & 2 layers of CFRP \\
\hline $\mathrm{HN}$ & 10011 & 300 & $35 \times 35$ & None & No \\
\hline $\mathrm{HRF}$ & 9668 & 300 & $35 \times 35$ & $20-\mathrm{mm}$ round corners & 2 layers of CFRP \\
\hline HLCF & 16454 & 300 & $35 \times 35$ & $\begin{array}{l}\text { Circularization with Full } \\
\text { length concrete } \\
\text { segments }\end{array}$ & 2 layers of CFRP \\
\hline HSCF & 10011 & 300 & $35 \times 35$ & $\begin{array}{l}\text { Circularization with } \\
\text { Short concrete segments }\end{array}$ & 2 layers of CFRP \\
\hline
\end{tabular}


Table 2. Test results of solid and hollow specimens

\begin{tabular}{lcccc|cccc}
\hline \multirow{2}{*}{ Specimen } & \multicolumn{4}{c}{ Solid specimens } & \multicolumn{4}{c}{ Hollow specimens } \\
\cline { 2 - 9 } & SN & SRF & SLCF & SSCF & HN & HRF & HLCF & HSCF \\
\hline Yield load (kN) & 508 & 561 & 975 & 647 & 441 & 520 & 872 & 580 \\
Axial deformation at yield load & 0.6 & 0.8 & 0.8 & 0.87 & 0.6 & 0.8 & 0.7 & 0.8 \\
$(\mathrm{~mm})$ & 514 & 805 & 1653 & 888 & 447 & 533 & 1237 & 751 \\
Ultimate axial load (kN) & 0.7 & 4 & 3.8 & 3.5 & 0.64 & 0.9 & 3 & 4 \\
Axial deformation at ultimate axial & & & & & & & & \\
load (mm) & 1.2 & 5.3 & 5.0 & 4.1 & 1.2 & 4.3 & 4.5 & 5.3 \\
Ductility & \multicolumn{1}{c}{} & & & & & & \\
\hline
\end{tabular}


Table 3. Theoretical and experimental results of the tested solid and hollow specimens

\begin{tabular}{lccc}
\hline \multirow{2}{*}{ Specimen } & \multicolumn{2}{c}{ Ultimate axial load $(\mathrm{kN})$} & \multirow{2}{*}{ Theoretical/Experimental (\%) } \\
\cline { 2 - 3 } & Experimental & Theoretical & \\
\hline SRF & 805 & 708 & 0.88 \\
SLCF & 1653 & 1299 & 0.79 \\
SSCF & 888 & 792 & 0.89 \\
HRF & 533 & 551 & 1.03 \\
HLCF & 1237 & 1078 & 0.87 \\
HSCF & 751 & 656 & 0.88 \\
\hline
\end{tabular}


Wrapping the top and bottom ends with two layers of CFRP with $50 \mathrm{~mm}$ width
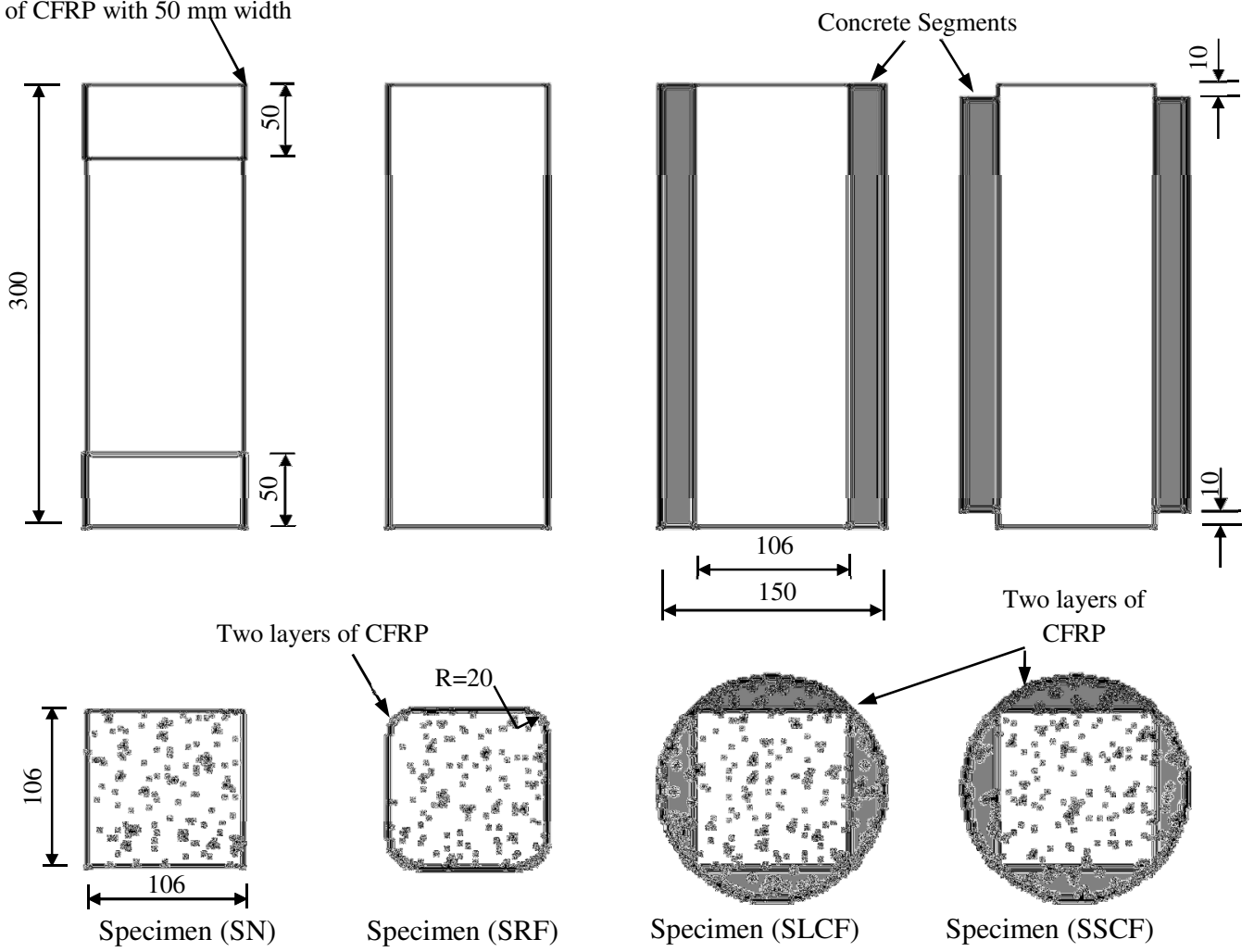

a) Solid Specimens

Wrapping the top and bottom ends with two layers of CFRP with $50 \mathrm{~mm}$ width
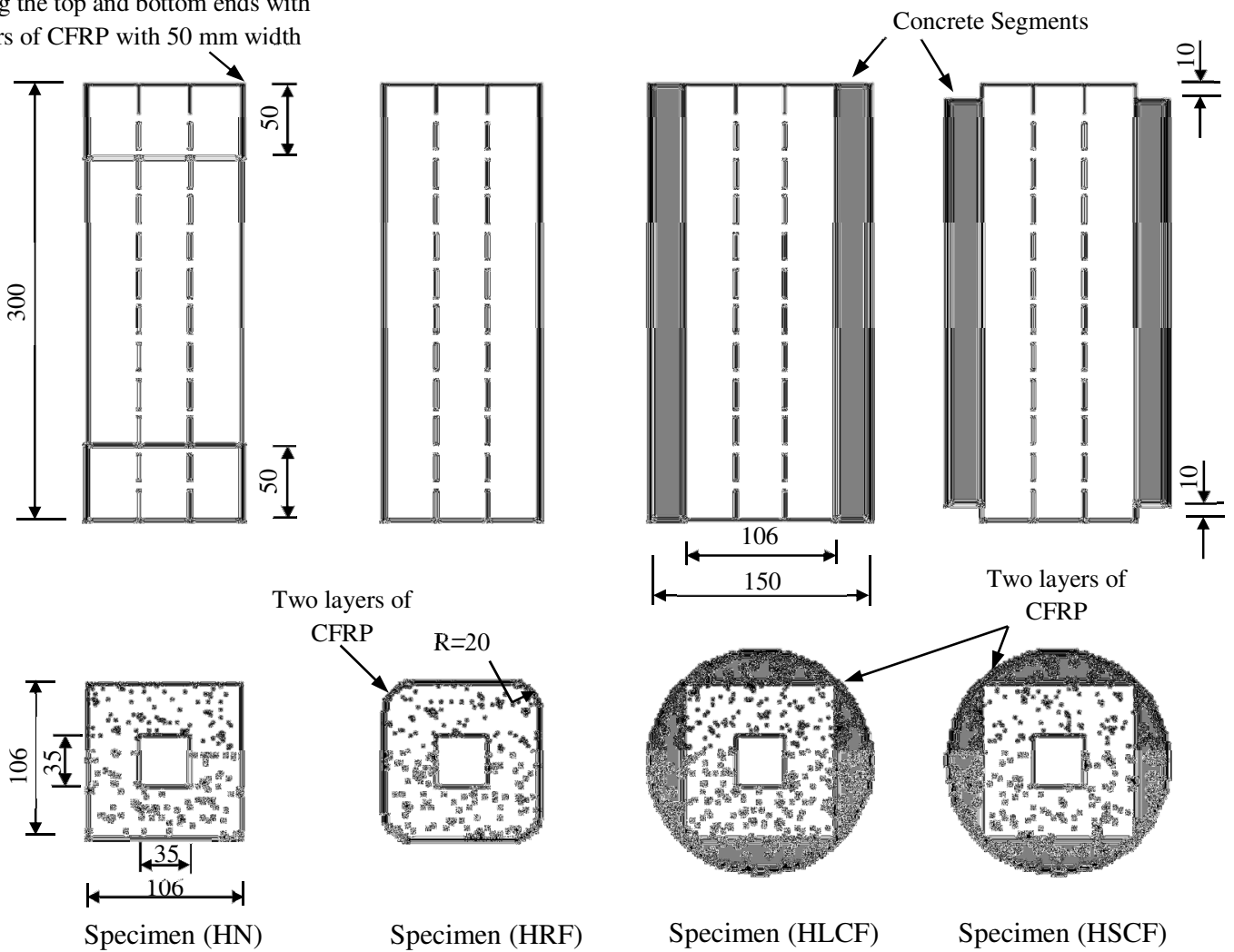

b) Hollow Specimens

Fig. 1: Schematic details of the specimens (all dimensions are in $\mathrm{mm}$ ) 


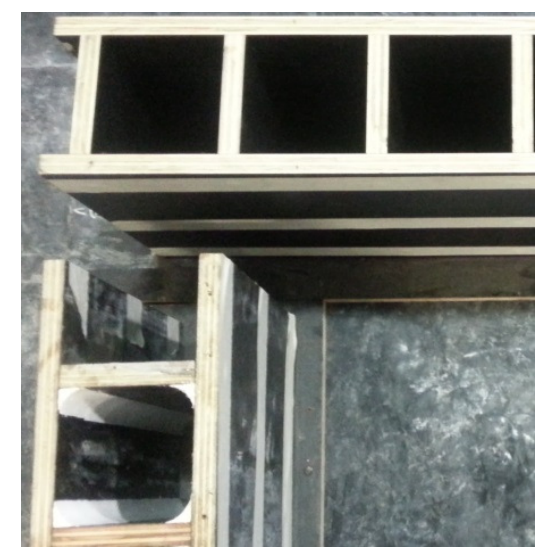


ERROR: undefined

OFFENDING COMMAND: ‘

STACK: 